\title{
POOR VISION AND RISK OF FALLS AND FRACTURES IN OLDER AUSTRALIANS : THE BLUE MOUNTAINS EYE STUDY
}

\author{
Rebecca Ivers \\ Institute for International Health \\ University of Sydney
}

\section{Robert Cumming}

Department of Public Health and Community Medicine

University of Sydney

\section{Paul Mitchell}

Department of Ophthalmology

Westmead Hospital, University of Sydney

Falls become more frequent with increasing age, and studies have shown that around a third of elderly people living in the community have one or more falls each year. The consequences of falls are significant and include injury, physical deterioration, fear of falling, institutionalisation, and in some instances death. ${ }^{1-10}$ It is well recognised that fall-related risk factors are a major contributor to hip fractures in the elderly. This article describes the Blue Mountains Eye Study, which systematically measured and graded visual function and eye disease in an older community-dwelling population. This study provides a good opportunity to examine the associations between poor vision, falls and hip fracture in an older population.

\section{BACKGROUND}

The consequences of a hip fracture for an independent living older person are great. ${ }^{11}$ In a recent study, Salkeld et al. (2000) found that 80 per cent of women surveyed would rather be dead than experience the loss of independence and quality of life that results from a bad hip fracture and subsequent admission to a nursing home. ${ }^{12}$ March et al. (1996) found that 12 months after hip fracture, among people who had been living in their own home prior to the fracture, 17.8 per cent were dead, 21.8 per cent had moved to a nursing home, and only 24 per cent were able to walk as well as they did prior to the fracture. ${ }^{13}$

\section{Visual impairment}

Many older people living in the community suffer from poor vision or eye disease. The prevalence of sightthreatening conditions such as cataract, glaucoma and macular degeneration all rise with age. ${ }^{14-18}$

Problems affecting vision are often treatable or preventable. For example, many older people could benefit from a change in their glasses' prescription. The Blue Mountains Eye Study found that 45 per cent of people would improve their visual acuity by one or more lines at testing with new glasses. ${ }^{19}$ The Melbourne Visual Impairment Project found that the number of people with visual impairment could be halved by the provision of a new spectacle correction. ${ }^{20}$ Much eye disease in the community is undiagnosed; for example, in the Blue Mountains Eye Study, 49 per cent of people identified with open-angle glaucoma were previously undiagnosed. ${ }^{18}$

\section{Vision as a risk factor for falls and fractures}

Other studies have found that contrast sensitivity, ${ }^{21-23}$ poor visual acuity, ${ }^{24-26}$ self-reported poor vision, ${ }^{27,28}$ impaired depth perception, ${ }^{5}$ and visual field impairment, ${ }^{29}$ were significantly associated with falls. There have also been several studies that have found that poor visual acuity was not related to falling; ; $, 2,5,21,22$ however, most of these studies evaluated only limited aspects of vision, such as visual acuity. No large community-based study has examined the relationship between falls and common ocular conditions in the elderly such as cataract, age related macular degeneration, glaucoma, or diabetes-related eye disease.

There have been three longitudinal studies that have examined the relationship between poor vision and hip fracture. ${ }^{30-32}$ The Framingham study found that for women with poor or moderately impaired vision, the risk of hip fracture was doubled, but that neither cataract nor other common eye diseases had an independent effect on fractures of the hip after adjusting for visual acuity. ${ }^{32}$ The EPIDOS (Epidémiologie de l'ostéoporose) study found reduced visual acuity was an independent predictor of hip fractures. ${ }^{30}$ However, the Study of Osteoporotic Fractures found that while poor contrast sensitivity and depth perception were associated with fractures, poor visual acuity was not. ${ }^{31}$

Previous studies of poor vision, falls and fractures have all lacked systematically-measured, well-validated measures of eye disease and visual function. While results of most previous studies suggest a relationship between measures of visual impairment and falls and fractures, they are also inconclusive as to which aspect of visual impairment is the most important.

\section{METHODS}

The Blue Mountains Eye Study is a population-based study of eye disease in older community dwelling people living in the Blue Mountains, west of Sydney. All residents aged 49 years and older living in two postcode areas (comprising Katoomba, Leura and Wentworth Falls) were eligible for inclusion in the study, and 3,654 individuals (82.4 per cent of the eligible population) were examined. The baseline examination consisted of an extensive eye examination and an interviewer administered questionnaire, including questions about falls in the last 12 months. Tests of vision performed included tests of 
visual acuity, contrast sensitivity (a measure of the ability to differentiate between objects of high and low contrast) and visual field (peripheral vision). Details of the study have previously been described. ${ }^{16-18,33}$

After five years, subjects were invited to return for further examination. Of the 3,654 participants in the baseline study, 2,326 (63.5 per cent) returned to the five year follow-up examination. Details of hip fractures were collected from self-report at the five year follow-up examination, and a search was made of radiology records and discharge summaries at the local hospital. All fractures were radiologically confirmed. Loss to follow-up was estimated to be around five per cent.

\section{RESULTS}

\section{Analysis of baseline cross-sectional data}

Of the 3,654 individuals in the baseline study, 3,299 (90.3 per cent) answered the questions about falls. Of those aged 65 years and over, 29.6 per cent reported one or more falls. Tests of visual function that had a statistically significant association with two or more falls after adjustment for confounders were visual acuity (prevalence ratio (PR) 1.9 for visual acuity worse than 20/30), contrast sensitivity (PR 1.2 for a one unit decrease at six cycles per degree) and visual field screening (PR 1.5 for five or more points missing). ${ }^{33}$ The presence of posterior subcapsular cataract (PR 2.1), and use of non-miotic glaucoma medication (PR 2.0) had a statistically significant association with two or more falls, while presence of agerelated macular degeneration, diabetic retinopathy and cortical or nuclear cataract did not. ${ }^{33}$

\section{Analysis of longitudinal data}

Analyses were carried out after both two and five years of follow-up. We believed that stronger associations for the shorter period were to be expected because the level of visual impairment present at the time of a hip fracture would be much better reflected by a recent eye examination than an eye examination performed many years in the past. There were 59 subjects who had sustained a fracture of the hip after five years of follow-up, and 17 subjects sustained a hip fracture after two years of followup. As expected, visual impairment of any type did not predict risk of hip fracture during five-year follow-up.

Risk factors that were predictive of hip fracture after two years of follow-up were:

- corrected visual acuity (that is, the best visual acuity attained after refraction);

- visual field deficits;

- presence of posterior subcapsular cataract (data as yet unpublished).

No other eye disease was predictive of hip fracture, probably because of the small numbers involved.

\section{CONCLUSION}

The Blue Mountains Eye Study has confirmed that visual impairment is strongly associated with an increased risk of falls and hip fracture. Having poor visual acuity, posterior subcapsular cataract or a visual field deficit were all associated with increased risk of both falls and hip fracture. Because of the frequency of visual impairment, it seems likely that a high proportion of falls and hip fractures are due to visual impairment. Ensuring that older people have access to regular eye examinations and have timely treatment for eye diseases, such as cataract, may substantially reduce the incidence of falls and subsequent hip fracture in the community.

\section{REFERENCES}

1. Tinetti ME, Speechley M, Ginter SF. Risk factors for falls among elderly persons living in the community. $N$ Engl $J$ Med 1988; 319: 1701-1707.

2. Campbell AJ, Borrie MJ, Spears GF. Risk factors for falls in a community-based prospective study of people 70 years and older. J Gerontol 1989; 44: M112-7.

3. O'Loughlin JL, Robitaille Y, Boivin JF, Suissa S. Incidence of and risk factors for falls and injurious falls among the community-dwelling elderly. Am J Epidemiol 1993; 137: 342354.

4. Sattin RW. Falls among older persons: a public health perspective. Annu Rev Public Health 1992; 13: 489-508.

5. Nevitt MC, Cummings SR, Kidd S, Black D. Risk factors for recurrent nonsyncopal falls. A prospective study. JAMA 1989; 261: 2663-2668.

6. Wolinsky FD, Fitzgerald JF, Stump TE. The effect of hip fracture on mortality, hospitalization, and functional status: a prospective study. Am J Public Health 1997; 87: 398-403.

7. Kiel DP, O'Sullivan P, Teno JM, Mor V. Health care utilization and functional status in the aged following a fall. Med Care 1991; 29: 221-228.

8. Dunn JE, Rudberg MA, Furner SE, Cassel CK. Mortality, disability, and falls in older persons: the role of underlying disease and disability. Am J Public Health 1992; 82: 395400.

9. Tinetti ME, Liu WL, Claus EB. Predictors and prognosis of inability to get up after falls among elderly persons. JAMA 1993; 269: 65-70.

10. Kosorok MR, Omenn GS, Diehr P, Koepsell TD, Patrick DL. Restricted activity days among older adults. Am J Public Health 1992; 82: 1263-1267.

11. Sernbo I, Johnell O. Consequences of a hip fracture: a prospective study over one year. Osteoporos Int 1993; 3: 148-53.

12. Salkeld G, Cameron ID, Cumming RG, et al. Quality of life related to fear of falling and hip fracture in older women: a time trade off study. BMJ 2000; 320: 341-6.

13. March L, Chamberlain A, Cameron I, et al. Prevention, treatment and rehabilitation of fractured neck of femur. Report from the Northern Sydney Area Health Service Fractured Neck of Femur Health Outcomes Project. Sydney: Northern Sydney Area Health Service, 1996; www.mja.com.au/public/ issues/iprs $2 /$ march/fnof.pdf $>$ ). 
14. Klein BE, Klein R, Linton KL. Prevalence of age-related lens opacities in a population. The Beaver Dam Eye Study. Ophthalmology. 1992; 99: 546-552.

15. Klein BE, Klein R, Sponsel WE, et al. Prevalence of glaucoma. The Beaver Dam Eye Study. Ophthalmology. 1992; 99: 14991504.

16. Mitchell P, Smith W, Attebo K, Wang JJ. Prevalence of Agerelated Maculopathy in Australia: The Blue Mountains Eye Study. Ophthalmology 1995; 102: 1450-1460.

17. Mitchell P, Cumming RG, Attebo K, Panchapakesan J. Prevalence of Cataract in an Australian Population: the Blue Mountains Eye Study. Ophthalmology 1997; 104: 581-588.

18. Mitchell P, Smith W, Attebo K, Healey PR. Prevalence of Open-angle Glaucoma in Australia: The Blue Mountains Eye Study. Ophthalmology 1996; 103: 1661-1669.

19. Attebo K, Mitchell P, Smith W. Visual acuity and the causes of visual loss in Australia. The Blue Mountains Eye Study. Ophthalmology 1996; 103: 357-364.

20. Taylor HR, Livingston PM, Stanislavsky YL, McCarty CA. Visual impairment in Australia: distance visual acuity, near vision, and visual field findings of the Melbourne Visual Impairment Project. Am J Ophthalmol 1997; 123: 328-37.

21. Lord SR, Clark RD, Webster IW. Physiological factors associated with falls in an elderly population. J Am Geriatr Soc 1991; 39: 1194-1200.

22. Lord SR, Clark RD, Webster IW. Visual acuity and contrast sensitivity in relation to falls in an elderly population. Age Ageing 1991; 20: 175-181.

23. Lord SR, Ward JA, Williams P, Anstey KJ. Physiological factors associated with falls in older community-dwelling women. J Am Geriatr Soc 1994; 42: 1110-1117.
24. Clark RD, Lord SR, Webster IW. Clinical parameters associated with falls in an elderly population. Gerontology 1993; 39: 117-123.

25. Tinetti ME, Williams TF, Mayewski R. Fall risk index for elderly patients based on number of chronic disabilities. $\mathrm{Am} \mathrm{J}$ Med 1986; 80: 429-434.

26. Jack CI, Smith T, Neoh C, Lye M, McGalliard JN. Prevalence of low vision in elderly patients admitted to an acute geriatric unit in Liverpool: elderly people who fall are more likely to have low vision. Gerontology 1995; 41: 280-285.

27. Perry BC. Falls among the elderly living in high-rise apartments. J Fam Pract 1982; 14: 1069-1073.

28. Lord SR, Ward JA, Williams P, Anstey KJ. An epidemiological study of falls in older community-dwelling women: the Randwick falls and fractures study. Aust J Public Health 1993; 17: $240-245$.

29. Glynn RJ, Seddon JM, Krug JH, Jr., et al. Falls in elderly patients with glaucoma. Arch Ophthalmol 1991; 109: 205210.

30. Dargent-Molina P, Favier F, Grandjean H, et al. Fall-related factors and risk of hip fracture: the EPIDOS prospective study. Epidemiologie de l'osteoporose. Lancet 1996; 348: 145-149.

31. Cummings SR, Nevitt MC, Browner WS, et al. Risk factors for hip fracture in white women. Study of Osteoporotic Fractures Research Group. N Engl J Med 1995; 332: 767-773.

32. Felson DT, Anderson JJ, Hannan MT, Milton RC, Wilson PW, Kiel DP. Impaired vision and hip fracture. The Framingham Study. J Am Geriatr Soc 1989; 37: 495-500.

33. Ivers RQ, Cumming RG, Mitchell P, Attebo K. Visual Impairment and Falls in Older Adults: The Blue Mountains Eye Study. J Am Geriatr Soc 1998; 46: 58-64. 哭

\section{REACHING THE COMMUNITY AND SPECIFIC POPULATIONS}

A Community and Specific Populations Advisory Council (CASPAC) has been formed to advise Fitness NSW on community fitness issues. CASPAC evolved from the former National Association for Gentle Exercise (NAGE). CASPAC will focus on two main issues in the short term:

- to determine the appropriate training requirements/ standards for fitness professionals to work with specific population groups (including older persons) and the availability of such training;

- to develop a strategy, in conjunction with the NSW Department of Health, to train fitness professionals to provide

fitness services that would support NSW Health's fall injury prevention initiatives.

If you would like to become involved with CASPAC or would like to contact members of the committee, please contact Fitness NSW on (02) 94606200 or email fitnessnsw@fitnessnsw.com.au. 